International Journal of Advanced Biological and Biomedical Research Available online at http:www.ijabbr.com

Volume 8, Issue 4 (2020) pp. 358-368

DOI: 10.33945/SAMI/IJABBR.2020.3.3

Review Article

\title{
Introduction and Evaluation of Three Types of Fine Grain Products and Their Harvesters
}

\author{
Pourya Bazyar*1, Ali Jafari1, Reza Alimardani1, Valiollah \\ Mohammadi², James Grichar ${ }^{3}$ \\ ${ }^{1}$ Department of Agricultural Machinery Engineering, Faculty of Agricultural Engineering \\ and Technology, University of Tehran, Karaj, Iran \\ 2Department of Agronomy and Plant Breeding, College of Agriculture, University of \\ Tehran, Karaj, Iran \\ ${ }^{3}$ Texas A\&M AgriLife Research, Department of Soil and Crop Sciences, USA, Corpus \\ Christi, TX \\ *Corresponding Author E-mail: pourya.bazyar@ut.ac.ir
}

Received: 13 March 2020, Revised: 30 April 2020, Accepted: 7 May 2020

\begin{abstract}
Fine grain products are harvested in two manual and mechanized forms. Nowadays, common combine harvesters are used, but fine grain products such as Rapeseed, Sesame and Sorghum cannot be harvested with conventional heads of combine harvesters due to the excessive grain loss in the head of the combine. Therefore, the necessity of design and fabricating machines and heads of combine harvesters became the center of attention to researchers because of the nutritional and medicinal benefits of fine-grain products. This research delves into an overview of the special headers and machines for harvesting three type of fine grain products with high loss and an evaluation of each of these harvesters.
\end{abstract}

Key words: Sesame, Rape, Canola, Harvester, Fine grain products

\section{Introduction}

The effort to achieve agricultural development depends on increased mechanization. Fine grain products such as Sesame (Sesamum indicum L.), Sorghum (Sorghum bicolor L. Moench), and Canola (Brassica napus L.) have been hand-picked in the past, while nowadays the use of special machines and heads of combine harvesters makes it easy to harvest. Now we take a look at the three types of fine gran products. S. Indicum L. (Sesame) is an ancient crop and has been cultivated in Asia for more than 5000 years (Akbar et al., 2011). Archeologic evidence has shown that Sesame seeds were cultivated in the Indus Valley between 1750 and $2250 \mathrm{BC}$, and more recent charred Sesame seeds have been found in Shahi-Tump and Qalat in Pakistan (Nadeem et al., 2015). The genus Sesamum (family Pedaliaceae) is 
comprised of about 37 species. S. Indicum is a well-known member of this genus and is widely cultivated. Other species including Sesamum angustifolium, Sesamum auriculatum, Sesamum prostratum, and Sesamum radiatum are cultivated at a smaller scale in Pakistan and other South Asian countries (Hwang, 2005). Since Sesame seeds contain a huge amount of oil (50\% to 60\%), it is regarded as the queen of oilseeds (Pham et al., 2010). Sesame is grown over 50 countries in the world (Akbar et al., 2011). China, India, Myanmar (Burma), Uganda, Turkey, Nigeria, Thailand, Bangladesh, Ethiopia, Mexico, and Pakistan are the major producers of Sesame. Sesame is known under different names depending on where you are in the world. It is usually known as til (Urdu, Hindi), hu-ma (Chinese), Sesame (French), goma (Japanese), gergelim (Portuguese), and ajonjoli (Spanish) (Anilakumar et al., 2010). Canola, also known as Rape, oilseed Rape, rapa, and Rapeseed is a bright yellow flowering member of the Brassicaceae family (mustard or cabbage family). Canola is widely cultivated throughout the world for the production of animal feed, vegetable fat for human consumption, and biodiesel. Leading producers include the European Union, Canada, the United States, Australia, China and India (Izli et al., 2009). World production is growing rapidly; Food and Agriculture Organization (FAO) reports say 48.97 million tons of Canola was produced in 2005 (FAO, 2006). Physical properties of Canola oils are essential for the operation of certain machineries or for determining their motor behavior for displacement (Sahay \& Singh, 1994). Sorghum is an important crop species in the United States and around the world. Because of its substantial heat and drought tolerance, Sorghum production is traditional in semi-arid, subtropical and tropical regions. In addition to abiotic stress tolerance, Sorghum is very responsive to more favorable conditions in terms of productivity. While primarily known as a cereal grain, Sorghum is grown throughout the world as a forage, syrup and more recently, energy crop. In 2008, U.S. farmers harvested about 2.9 million hectares of grain Sorghum (Rooney, 2014).

This research was based on the need for the use of special combine headers for harvesting fine grain products; accordingly, the construction and design of these headers and combines have been studied.

\section{Sesame harvesters}

(Zhidong and $\mathrm{Na}$, 2015) coined a Sesame cutting and harvesting machine (Figure 1). This machine consists of a tractor, reel, screw conveyor, belt conveyor and collection tank. The reel, cutter, screw conveyor and conveyor belt are arranged on a frame at one end of the tractor. Moreover, there is a collection box in the other end of the tractor. Therefore, the reel, which is arranged on the frame, rotates along an anti-clockwise direction to stir Sesame stalks, and the tips of the Sesame stalks clockwise tilt to a ground moving direction under stirring of the reel. In addition, the cutter is composed of a disc cutting knife and a hydraulic motor. First, the disc cutting knife rotates under driving of the hydraulic motor. It then approaches the ground and cuts off the Sesame stalks. Next, the Sesame stalks fall into the screw conveyor. After dropping, the screw conveyor is divided into two sections (one end of the screw conveyor rotates towards the left side while the other end of the screw conveyor rotates towards the right side). In the next part, the Sesame stalks come together to the middle part of the screw conveyor and enter the conveyor belt. In the end, they are delivered to the belt conveyor by the conveyor belt, and the belt conveyor accelerates to throw the Sesame stalks into the collection box (Zhidong \& $\mathrm{Na}$, 2015). 


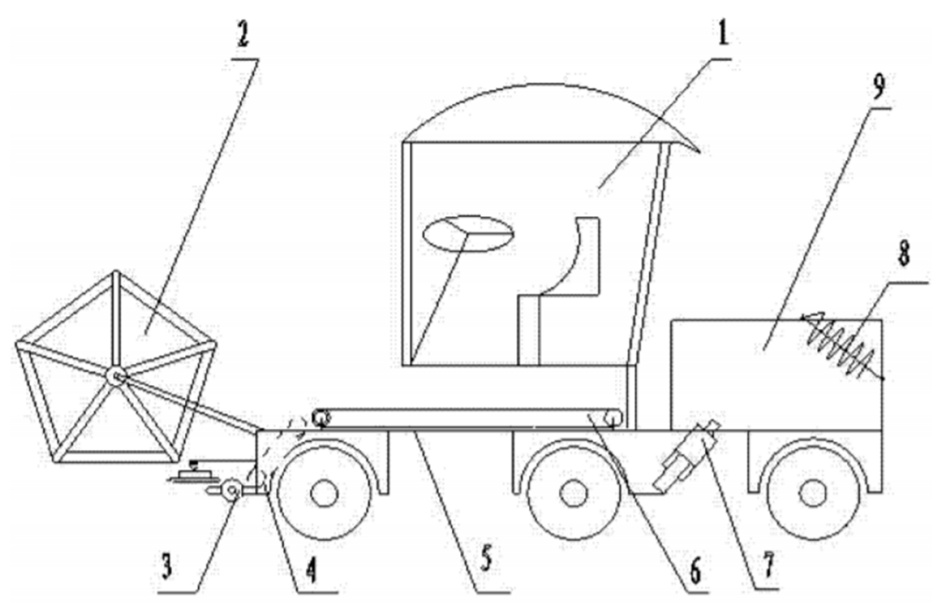

Figure 1. Sesame cutting and harvesting machine

(Ahn, 2019) developed a Sesame's grain harvester includes frame (Figure 2), rotating shaft, rotating wheel, fitting groove, shear flange, rear flange, belt, belt pulley, regulating lever, power generating means, impact generating means, spring portion, support portion, operation control unit, tongs, tongue support plate, band, spindle. The rotating shaft extends in a horizontal direction with the rotating wheel having a center. In terms of forming plurality of fitting grooves on the outer circumferential surface of the rotary wheel, they are formed by lining the outer circumferential surface of the rotary wheel with a gap. Furthermore, a part of the fitting groove has a close contact with a part of the outer circumferential surface of the rotary wheel. In addition, there is a power generating means for rotating one of the belt pulleys. To add to this, the power generating means causes rotating shaft and rotate the belt in a repetitive manner (Ahn, 2019).

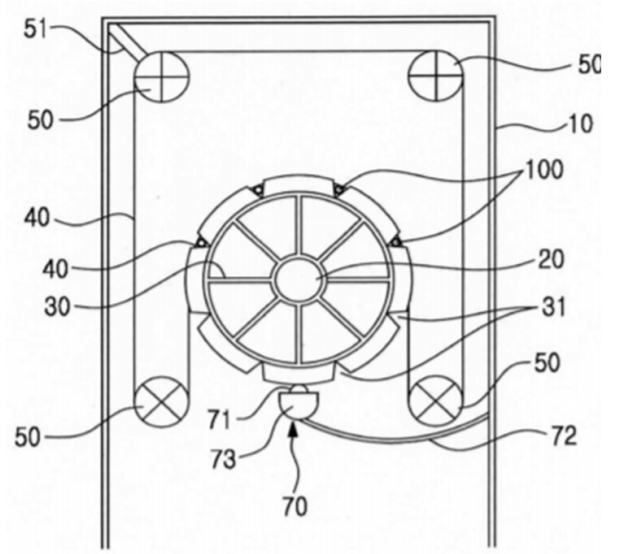

Figure 2. Sesame's grain harvester

(Bazyar et al., 2019) invented a small-scale combine head for harvesting fine-grain products (Figure 3), specifically for Sesame (Bazyar \& Jafari, 2019). The design of this machine was the need to reduce grain loss. It should be noted that this machine needs manpower to move and advance. The main parts of the machine include the collection tank, product cutting unit, separator unit with high elevation, and the stair frame system with a nylon cover. First, the bowls with the overlap between them make the stem of the cereal crop pass through these fingers. The 
stem is then bent and directed to the incision in the head. The presence of long dividers in the head, with a high-height nylon cover, eliminates the possibility of any grain shedding from the head and any spillage is poured into the bowl. Other specifications of the machine are Dimensions of the blade $20 * 30 \mathrm{~cm}$, Dimensions of the profile $2 * 2 \mathrm{~cm}$, Sheet thickness $2 \mathrm{~cm}$, Angle between two blades $108^{\circ}$, Machine height $1.3 \mathrm{~m}$, working width $60 \mathrm{~cm}$, Machine weight $38 \mathrm{~kg}$, Machine volume $0.04 \mathrm{~m}^{3}$, center of gravity $(\mathrm{X}=0.65, \mathrm{Y}=0.75, \mathrm{Z}=1.02) \mathrm{m}$, tank volume $0.216 \mathrm{~m}^{3}$ (Bazyar, 2020). The result of this research demonstrates that its head loss is about 16\% (less than the head loss of ordinary headers). However, this was constructed with the least cost. Due to the sloping design of these fingers, the grains inside the bowl are directed to the grain collection reservoir. The result of this research demonstrates that grain head loss is about $16 \%$ (less than the head loss of ordinary headers). Also, this unit was constructed cheaply (Bazyar et al., 2019).

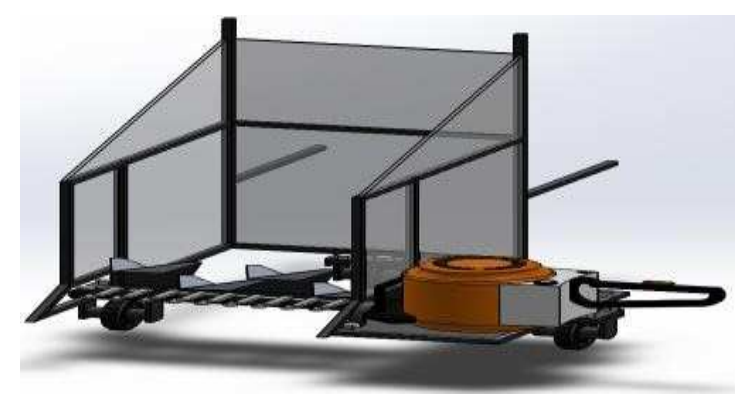

Figure 3. Small scale head of combine harvester for harvesting Sesame

\section{Canola harvesters}

(Helin et al., 2003) designed a Rape's cutting platform (Figure 4), including steel frame, a front mounted transverse cutter blade, switching mechanism, divider mechanism. The present invention is placed in front of a conventional combine harvester. Moreover, there is a docking station which is attached to Rapeseed cutter. To be more precise, when the transverse cutting movement of the cutting blade 2 obtains power, the Canola will be into close contact with platform's vertical cutting section. Also, vertical crop dividers play a role of cutting crop dividers, and it causes increasing the original depth. Lengthening the cutting station makes the cutter facilitate cutting all the grain and stalk of Rape. Furthermore, it aids to resist against falling of Rapeseeds (Helin et al., 2003).

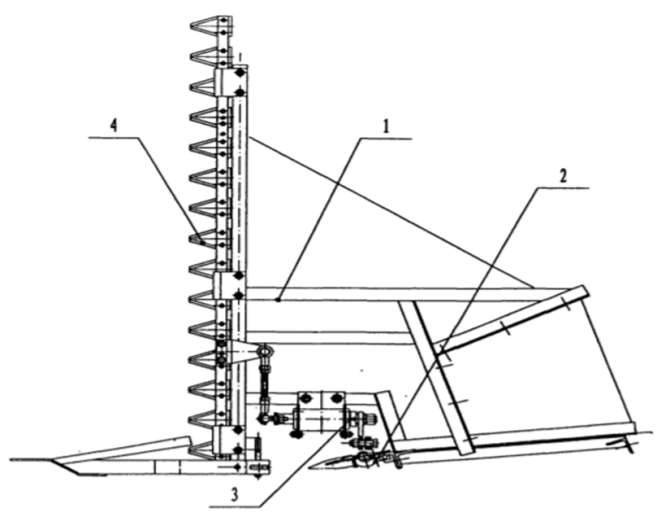

Figure 4. The Rape's cutting platform 
(Chengqian et al., 2012) invented a Rape cutter-rower (Figure 5) which helps to solve the problem of harvesting process of the Rape. The Rape cutter-rower comprises a rack which can be hung to the front part of a combine harvester, a reel arranged at the front upper part of the rack, and a cutting mechanism and a conveying mechanism which are driven by a power transmission mechanism, wherein the cutting mechanism comprises a vertical cutting knife and a horizontal cutting knife; the horizontal cutting knife is located at the front lower part of the rack, and the vertical cutting knife is located on one side of the rack. The conveying mechanism comprises a transverse conveyor belt arranged in the middle position of the rack, and a Rape discharging hole is formed at the end of the transverse conveyor belt, which is away from the vertical cutting knife. The conveying mechanism further comprises a transverse shifting mechanism arranged at the upper part of the discharging hole, and a longitudinal shifting mechanism arranged at the rear lower part of the Rape discharging hole. Accordingly, by arranging the transverse shifting mechanism and the longitudinal shifting mechanism, the Rape cutter-rower can smoothly discharge and row the cut Rape in an orderly way, thus avoiding the shattering damage and improving the yield of Rape (Chengqian et al., 2012).

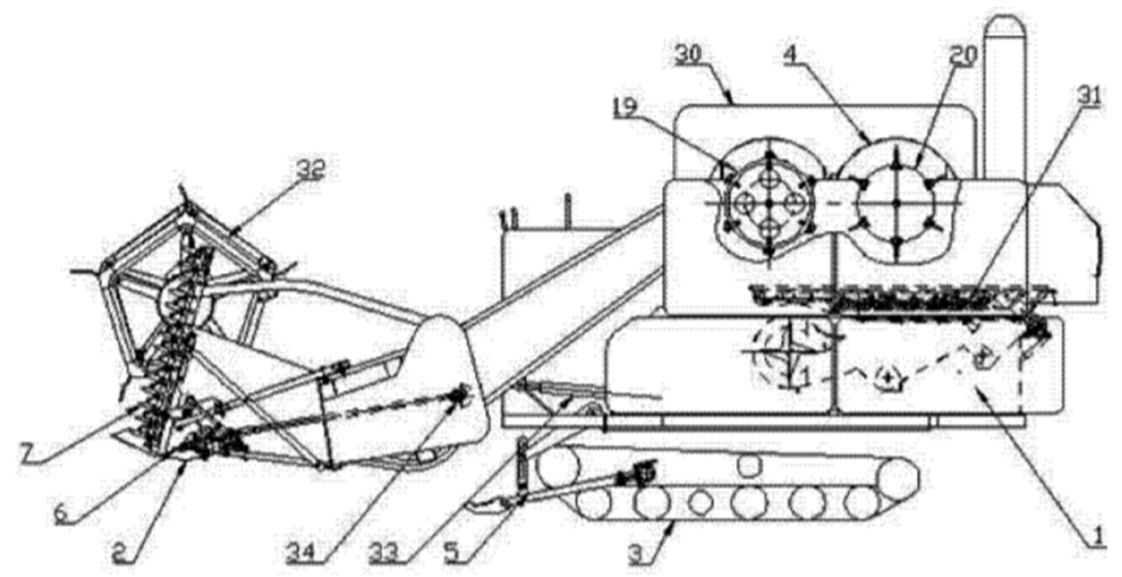

Figure 5. A Rape cutter-rower

\section{Sorghum harvesters}

(Yanmin, 2017) designed an automatic Sorghum harvesting device (Figure 6). This device comprises a rectangular base, a rectangular box which is fixedly connected to the upper surface of the rectangular base, an automatic harvesting mechanism which is arranged in the rectangular box, a collecting mechanism which is arranged on the side surface of the rectangular box, a mobile mechanism which is arranged at the edge of the lower surface of the rectangular base, a swinging sizing mechanism which is arranged on the lower surface of the rectangular base, a storage battery which is arranged on the upper surface of the rectangular box, a controller which is arranged on the side surface of the rectangular box, and the input end of the controller which is electrically connected with the storage battery through a wire. The automatic Sorghum harvesting device has the advantages of being simple in structure and high in practicability (Yanmin, 2017). 


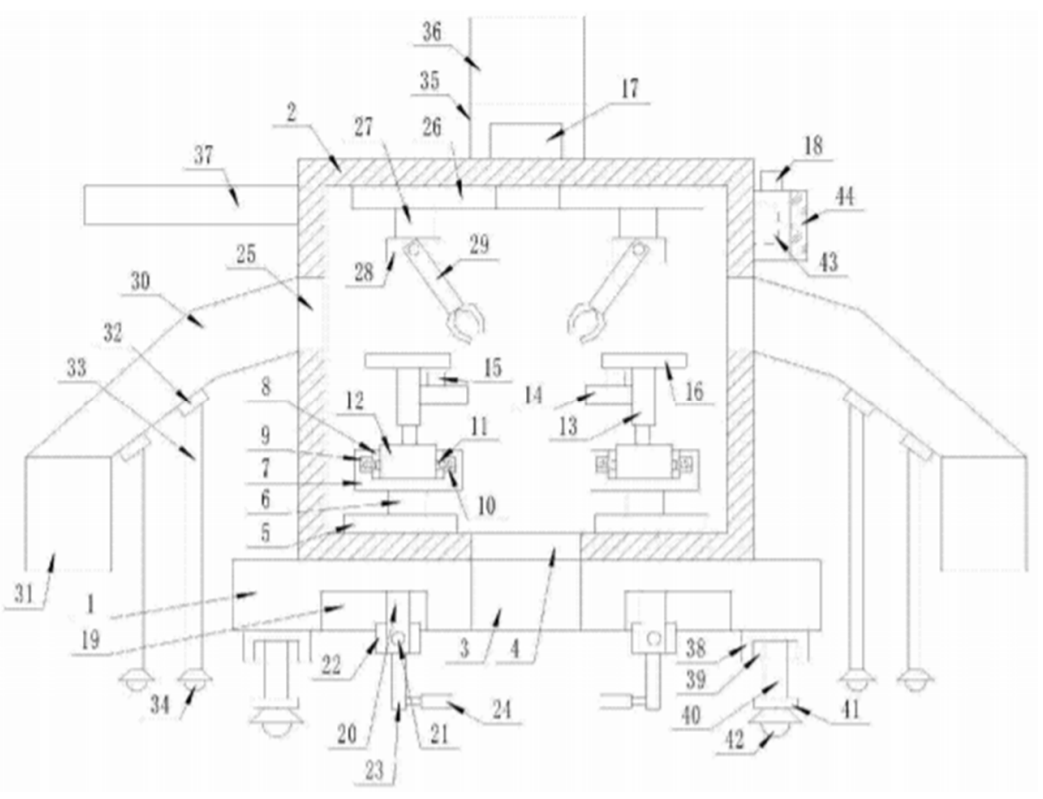

Figure 6. An automatic Sorghum harvesting device

(Ryadnov et al., 2019) designed a cereal Sorghum harvesting machine (Figure 7) containing a self-propelled chassis, a hydraulic weighed portion, a hopper, a harvester, a plant conveyor, a direct-flow external threshing chamber, a normalizer, an intermediate conveyor, a synchronizing gear, a grinder of plants and a spreader of ground mass. Harvester is additionally equipped with grain feeding system from forward-flow remote threshing chamber to hopper and mechanism of hopper replacement filled with grain till preset mass with empty replaceable hoppers. Mechanism for replacing the hopper with empty replaceable hoppers consists of a base on which a hopper is fixed, and a platform is connected to the base by a movable joint and fixed on a self-propelled chassis. The base is equipped with end sensor and is made of two guides, having equal length to two longitudinal dimensions of hopper (Ryadnov et al., 2019).

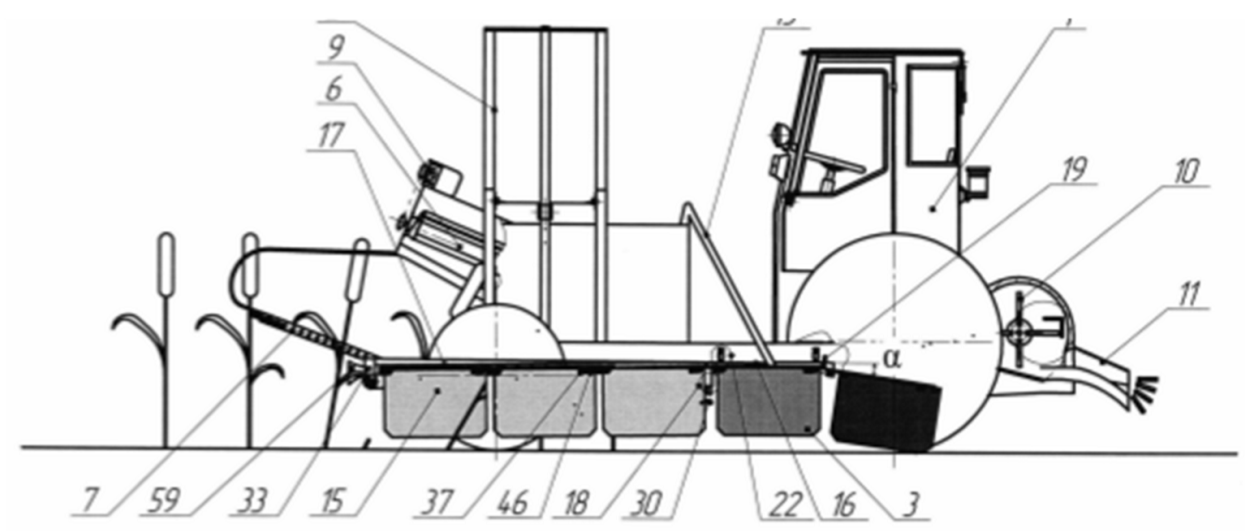

Figure 7. A cereal Sorghum harvesting machine 
This research was designed to facilitate researchers' studies on special heads of combine harvesters and harvesting machines for fine grain products and their advantages and disadvantages.

\section{Results and discussions}

In this research, to select the best header for harvesting fine-grain crops (Amir Fazli, 2001), all of the designs were evaluated. These designs were evaluated according to certain parameters including energy consumption, ease of maintenance, weight of the header, number of moving parts, cost of production, convenience of shipping, ability to stay stable and not move to either side, and transfer grain to a reservoir (Figure 7). Although each of the crops mentioned has different physical properties, these headers have a high grain loss and there should be a mechanism for reducing this loss. Canola and Sorghum have the same mass (about $0.0040 \mathrm{gr}$ ) at a moisture content of $4.7 \%$ (Tables 1,2). Sesame seed have the least mass (about 0.00203gr) (Table 3). Although the length of Sesame seed is more than Canola (about $0.73 \mathrm{~mm}$ ), the width of Canola seed is more than Sesame seed (about $0.15 \mathrm{~mm}$ ) at a moisture content of $4.7 \%$. In conclusion, each of these crops requires their own specific header and there is no single header which is able to harvest all of these crops (Simonyan, et al., 2007; Çalışır et al., 2005; Tunde-Akintunde et al., 2004).

Table 1. Some dimensional properties of Canola at different moisture contents d.b.\%

\begin{tabular}{cccc}
\hline Properties & $\mathbf{4 . 7 0 \%}$ & $\mathbf{1 3 . 1 4 \%}$ & $\mathbf{2 3 . 9 6 \%}$ \\
\hline Mass $(\mathrm{g})$ & $0.0040 \pm 0.0001$ & $0.0058 \pm 0.0001$ & $0.0065 \pm 0.0001$ \\
Length $(\mathrm{mm})$ & $2.07 \pm 0.016$ & $2.19 \pm 0.014$ & $2.29 \pm 0.015$ \\
Diameter $(\mathrm{mm})$ & $1.84 \pm 0.016$ & $1.90 \pm 0.013$ & $1.99 \pm 0.010$ \\
Geometric mean diameter $(\mathrm{mm})$ & $1.91 \pm 0.015$ & $1.99 \pm 0.012$ & $2.08 \pm 0.001$ \\
Sphericity (-) & $0.93 \pm 0.005$ & $0.92 \pm 0.004$ & $0.91 \pm 0.004$ \\
Volume $\left(\mathrm{mm}^{3}\right)$ & $3.96 \pm 0.085$ & $5.04 \pm 0.075$ & $5.15 \pm 0.075$ \\
\hline
\end{tabular}

Table 2. Mean physical properties of Sorghum grain and their skewness and kurtosis

\begin{tabular}{ccccc}
\hline & Mass, $\mathbf{g}$ & Projected area, $\mathbf{~ c m}^{\mathbf{2}}$ & Volume, $\mathbf{c m}^{\mathbf{3}}$ & $\begin{array}{c}\text { Particle density, } \\
\mathbf{g} / \mathbf{c m}^{\mathbf{3}}\end{array}$ \\
\hline No of samples & 30 & 30 & 30 & 30 \\
Values & $0.044^{*} \pm 0.007^{* *}$ & $4.66 \pm 0.85$ & $0.091 \pm 0.04$ & $1.02 \pm 0.2$ \\
Skewness, $\Gamma^{1}$ & 0.88 & 1.23 & -0.50 & 1.22 \\
Kurtosis, $\Gamma^{2}$ & -1.00 & 5.26 & 1.41 & 7.31 \\
\hline
\end{tabular}

*Mean values of 30 replicates

**Standard error

$\Gamma^{1}=$ skewness which characterizes the degree of symmetry of a distribution around its means. Positive skewness indicates a distribution with an asymmetric tail extending towards more values. Negative skewness indicates a distribution with an asymmetric tail extending towards more negative values. Zero values indicate symmetrical distribution.

$\Gamma^{2}=$ kurtosis which characterizes the relative peakness or flatness of a distribution compared to the normal distribution. Positive kurtosis indicates leptokurtic distribution. Negative 
kurtosis indicates platykurtic distribution. Zero values indicate normal or mesokurtic distribution.

Table 3. Some physical properties of Sesame seed

\begin{tabular}{cccc}
\hline Physical properties & $\begin{array}{c}\text { Number of } \\
\text { observations }\end{array}$ & Mean value & $\begin{array}{c}\text { Standard } \\
\text { Deviation }\end{array}$ \\
\hline Length L, mm & 20 & 2.80 & 0.32 \\
Width W, mm & 20 & 1.69 & 0.19 \\
Thickness T, mm & 20 & 0.82 & 0.10 \\
Geometric mean dia, mm & 20 & 1.56 & 0.17 \\
Sphericity & 20 & 0.56 & 0.09 \\
Surface area, $\mathrm{mm}^{2}$ & 20 & 7.80 & 0.47 \\
Mass of 100 seeds, g & 60 & 0.203 & 0.03 \\
Volume of 100 seeds, cm ${ }^{3}$ & 60 & 0.167 & 0.02 \\
True density, kg m ${ }^{-3}$ & 60 & 1224 & 0.24 \\
Bulk density, kg m ${ }^{-3}$ & 10 & 580 & 0.05 \\
Angle of repose, deg & 10 & 32.0 & 2.46 \\
Static coefficient of friction on & & & \\
Glass & 10 & 0.39 & 0.04 \\
Galvanized sheet & 10 & 0.41 & 0.04 \\
metal & & & \\
Mild steel & 10 & 0.52 & 0.07 \\
plywood & 10 & 0.54 & 0.05 \\
\hline
\end{tabular}

The combine headers designed by (Zhidong and $\mathrm{Na}$, 2015) prevented Sesame seed from falling to the ground. In a study, (Bazyar et al., 2019) designed bowl fingers with an overlap and stair frame to reduce the amount of head loss in harvesting Canola. The result of the research demonstrated that head loss was less than 16\% (Table 4) and it is suitable for harvesting both Canola and Sesame (Bazyar et al., 2019). Further, Bazyar's harvester has enough stability when it is worked by technician in the farm (Bazyar et al., 2020). To add to this, Ahn's harvester has a rotating shaft extending in a horizontal direction and the rotating wheel having a center. These mechanisms cause improving harvesting time and farm capacity. However, it swells the amount of head loss by drastic fluctuation of Sesame stems (Zhidong \& Na, 2015, Ahn, 2019, Bazyar et al., 2019).

Table 4. Loss Quantities of Bazyar's harvester

\begin{tabular}{cc}
\hline & Crete \\
\hline 10626 & Crete 1 \\
978 & Crete 2 \\
7924 & Crete 3 \\
12860 & Crete 4 \\
11470 & Crete 5 \\
6620 & Crete 6 \\
16 & Percentage of casualties \\
\hline
\end{tabular}


The header which is designed for harvesting Canola by (Helin et al., 2003) operates with two cutting (vertical and horizontal) systems and reduces the friction between the plants, so the grain loss is reduced; however, this header is specific to Canola and is not suitable for other fine grain products. However, the design for harvesting Canola by (Helin et al., 2003) has less power consumption than the header which is coined by (Chengqian et al., 2012) due to the usage of an additional sections of Chengqian et al. harvester. Also, the header designed by (Bazyar et al., 2019) is used for harvesting Canola but it is predicted that it has more head loss that other harvesters for harvesting Canola because of the lack of vertical cutter. In terms of farm capacity and maneuvering ability, all of the proposed headers have high maneuverability and farm capacity because of the connection to the combine harvester except of Bazyar et al., harvester. Considering the results mentioned above, the header designed by (Chengqian et al., 2012) harvester is suitable because of the use of a specific mechanism for cutting Canola stems and it has high farm capacity for this plant (Helin et al., 2003; Chengqian et al., 2012; Bazyar et al., 2019). The combine header for harvesting Sorghum designed by (Ryadnov et al., 2019) is specially designed for use on Sorghum and its disadvantages are greater than its benefits. Also, it is not appropriate for harvesting Canola or Sesame due to the lack of a lost grained collecting system. For other fine-grain cases, the use of harvesting machine designed by (Ryadnov et al., 2019) is the most suitable option because it has a complete system from harvesting to separating the seed from the pod, and it does not need to be connected to the combine. (Yanmin's, 2017) harvester features include having more accuracy than those of (Ryadnov et al., 2019). Additionally, it has the least power consumption because of using special sensors. Moreover, it has less tools than Ryadnov et al., harvester. Finally, it is appropriate for little farms because of its high precision (Ryadnov et al., 2019; Yanmin, 2017).

Table 5. A comparison of refined creative designs of the different combine heads

\begin{tabular}{|c|c|c|c|c|c|c|c|c|c|}
\hline D & $\mathrm{F}$ & $E$ & $\mathrm{D}$ & $\mathrm{C}$ & B & A & $\begin{array}{c}\text { Criteria } \\
\text { Weight }\end{array}$ & Criteria & $\begin{array}{c}\text { Standard } \\
\text { Number }\end{array}$ \\
\hline- & + & - & - & + & - & - & 6 & Energy consumption & 1 \\
\hline- & + & - & - & + & + & - & 1 & Easy to maintain & 2 \\
\hline- & + & - & - & + & + & - & 2 & $\begin{array}{l}\text { Weight of the } \\
\text { machine }\end{array}$ & 3 \\
\hline- & + & - & - & + & + & - & 7 & $\begin{array}{l}\text { Authenticity low } \\
\text { number of pieces }\end{array}$ & 4 \\
\hline- & - & - & - & + & - & - & 8 & Cost of production & 5 \\
\hline+ & - & + & + & - & - & + & 3 & $\begin{array}{c}\text { Convenience of } \\
\text { shipping }\end{array}$ & 6 \\
\hline+ & - & + & - & + & - & - & 5 & $\begin{array}{l}\text { Failure to loss to } \\
\text { either side }\end{array}$ & 7 \\
\hline+ & - & + & - & - & + & + & 4 & $\begin{array}{l}\text { Transfer grain to } \\
\text { reservoir }\end{array}$ & 8 \\
\hline $24(-)$ & $20(-)$ & $24(-)$ & $33(-)$ & $7(-)$ & $22(-)$ & $29(-)$ & & Negative point & \\
\hline $12(+)$ & $16(+)$ & $12(+)$ & $3(+)$ & $29(+)$ & $14(+)$ & $7(+)$ & & Positive point & \\
\hline $12(+)$ & $4(-)$ & $12(-)$ & $30(-)$ & $22(+)$ & $8(-)$ & $22(-)$ & & Total point & \\
\hline
\end{tabular}

In Table 5, inventions (Zhidong and $\mathrm{Na}$, Ahn, Bazyar, Helin, Chengqian, Yanmin, Ryadnov) are named A, B, C, D, E, F, G, respectively. As shown in Table 1, harvesters which are invented 
by (Bazyar et al., 2020) have the best quality than other types for harvesting fine-grain products due to their construction costs (Bazyar, 2020).

\section{Conclusions}

As the cultivation area of fine grain products are increasing in the world, there are many industrial and pharmaceutical properties for these three types of fine grain products, namely Sesame, Canola, Sorghum. Moreover, the consumption of oil seeds like Sesame and Canola are peaking by flying time throughout the world. Further, it is often harvested manually in some countries because of the high head loss in common combine harvesters, which is costly and time-consuming. However, in some other countries it is carried out by combine harvesters, which is a special head of combine harvester for fine grain products. In this research, three types of fine grain products were considered and the results reveal that Canola and Sesame are more sensitive against cutter force than Sorghum. Furthermore, Canola has high height and it needs vertical cutter for dipping head loss. To add to this, dividers should be manufactured with high height for Sesame and Canola. In this study some of the related inventions were evaluated and outcomes demonstrates that Bazyar et al.'s harvester has the best quality than others due to the costs of construction and harvesting results.

\section{Acknowledgements}

I appreciate the help of the manager and authorities at the Department of Agriculture Machinery from the University of Tehran for helping me with the construction of the harvester. Moreover, thanks to the authorities of the farm of the Seed Breeding Research Institute in Karaj, Iran.

\section{References}

Ahn, S. (2019). Sesame's grain harvester (patent). Application number: KR20190034056A. p. 1-2.

Akbar, F, Rabbani, MA, Masood, MS, Shinwari, ZK. (2011). Genetic diversity of sesame (Sesamum indicum L.) germplasm from Pakistan using RAPD markers. Pak. J. Bot, 43(4):2153-2160.

Amir Fazli, A. (2001). Design methods in engineering. Publication of Sharif University. First edition. P. 2530.

Anilakumar, KR, Pal, A, Khanum, F, Bawa, AS. (2010). Nutritional, medicinal, and industrial uses of Sesame (Sesamum indicum L.) seeds-an overview. Agricul. Conspect. Sci., 75:159e168.

Bazyar, P. (2020). Fine grain Products and their harvesters. Lambert academic publishing. p. 59-60.

Bazyar, P, Jafari, A. (2019). Head of combine harvester for harvesting Sesame consist of bowl finger and stair chasis mechanisms (patent). Application number: A01D41/00. P. 1-2.

Bazyar, P, Jafari, A, Alimardani, R, Mohammadi, V. (2019). Small-scale head of combine for harvesting Sesame. Agricul. Eng., 22(4):02.

Bazyar, P, Jafari, A, Alimardani, R, Mohammadi, V, Grichar, J. (2020). Finite Element Analysis of Small-scale Head of Combine Harvester for Harvesting Fine-Grain Products. Int. J. Adv. Biol. Biomed. Res., 2020, 8(4):339-357. 
Çalışır, S, Marakoğlu, T, Öğüt, H, Öztürk, Ö. (2005). Physical properties of Rapeseed (Brassica napus oleifera L.). J. Food Eng., 69(1):61-66.

Chengqian, J, Chongyou, W, Yan, L, Mei, J, Wensheng, Y, Lei, S, Zongyi, T. (2012). A Rape cutter-rower (patent). Application number: CN101822149B. p. 1-2.

FAO, (2006): Production, yield, harvested area values of Rapeseed. Available from FAOSTAT (October 2008).

Helin, H, Changxing, L, Jirong, F, Xiongqiang, C, Chunhua, Z, Jianxiong, Y, Xumao, F, Linfu, B, Junyan, G, Wenzhou, D, Hui, Y. (2003). Rape's cutting platform (patent). Application number: CN2582350Y. p. 1-2.

Hwang, LS. (2005). Sesame Oil. Bailey's Industrial Oil and Fat Products.

Izadinia, Y, Asudar, MA, Shafeinia, AS. (2005). Evaluation of Rapeseed mortality in direct harvesting by three types of combine platforms. National Conference on Agricultural Waste Disposal. Pages 51-59.

Izli N, Unal, H, Sincik, M. (2009). Physical and mechanical properties of Rapeseed at different moisture content. Int. Agrophys., 23(2):137-145.

Nadeem, A, Kashani, S, Ahmed, N, Buriro, M, Saeed, Z, Mohammad, F, Ahmed, S. (2015). Growth and yield of sesame (Sesamum indicum L.) under the influence of planting geometry and irrigation regimes. Am. J. Plant Sci., 6(07):980.

Pham, TD, Thi Nguyen, TD, Carlsson, AS, Bui, TM. (2010). Morphological Evaluation of Sesame ('Sesamum indicum'L.) Varieties from Different Origins. Aust. J. Crop Sci., 4(7):498.

Rooney, WL. (2014). Sorghum. Cellulosic energy cropping systems, 109-12.

Ryadnov, AI, Sharipov, RV, Fedorova, OA, Semchenko, AV. (2019). Cereal Sorghum harvesting machine (patent). Application number: RU2703429C1.p.1-2.

Sahay, KM, Singh, KK. (1996). Unit operations of agricultural processing. Vikas Publishing House Pvt. Ltd.

Simonyan, KJ, El-Okene, AM, Yiljep, YD. (2007). Some physical properties of Samaru Sorghum 17 grains: https://ecommons.cornell.edu/handle/1813/10654

Tunde-Akintunde, TY, Akintunde, BO. (2004). Some physical properties of sesame seed. Biosystem. Eng., 88(1):127-129.

Yanmin, M. (2017). An automatic Sorghum harvesting device (patent). Application number: CN106416605A. p. 1-2.

Zhidong, G, Na, Z. (2015). Sesame cutting and harvesting machine (patent). Application number: CN104380913A.p. 1-2.

How to cite this article: Pourya Bazyar*, Ali Jafari, Reza Alimardani, Valiollah Mohammadi, Introduction and Evaluation of Three Types of Fine Grain Products and Their Harvesters. International Journal of Advanced Biological and Biomedical Research, 2020, 8(4), 358-368. Link: http://www.ijabbr.com/article_39702.html 